\title{
Errata
}

\section{The World of Diabetologia in 1999 (Editorial)}

Diabetologia (1999) 42: 1-2

\section{W. Waldhäusl}

On page 1 , second column, line 29 should read:

... diabetology. Up until now there has been a tendency to reinvent the rules

of internal medicine which are to treat nephropathy and hypertension whenever they occur.

This time something new has been added. Some puzzle...

\section{Intramyocellular lipid concentrations are correlated with insulin sensitivity in humans: a ${ }^{1} \mathbf{H}$ NMR spectroscopy study (Rapid communication)}

\author{
M. Krssak ${ }^{1}$, K. Falk Petersen ${ }^{1}$, A. Dresner ${ }^{1}$, L.DiPietro ${ }^{2}$, S.M. Vogel ${ }^{1}$, D. L. Rothman ${ }^{1}$, M. Roden ${ }^{4}$, G. I.Shulman ${ }^{3}$ \\ ${ }^{1}$ Department of Internal Medicine Yale University School of Medicine, New Haven, Connecticut, USA \\ ${ }^{2}$ The John B.Pierce Laboratory and Department of Epidemiology \& Public Health Yale University School of Medicine, \\ New Haven, Connecticut, USA \\ ${ }^{3}$ Howard Hughes Medical Institute, Yale University School of Medicine, New Haven, Connecticut, USA \\ ${ }^{4}$ Division of Endocrinology and Metabolism, Department of Internal Medicine III, University of Vienna, Vienna, Austria \\ Diabetologia (1999) 42: 113-116
}

This is the corrected list of the authors for this article. 